World Lumen Congress 2021 | May 26-30, 2021 |

Iasi, Romania

\title{
The Role of Biomimicry on Visual Design Education
}

\author{
Ufuk BAKAN, Uğur BAKAN
}

https://doi.org/10.18662/wlc2021/05

How to cite: Bakan, U., \& Bakan, U. (2021). The Role of Biomimicry on Visual Design Education. In A. Sandu (vol. ed.), Lumen Proceedings: Vol. 17 World Lumen Congress 2021 (pp. 46-52). Iasi, Romania: LUMEN Publishing House. https://doi.org/10.18662/wlc2021/05 


\title{
The Role of Biomimicry on Visual Design Education
}

\author{
Ufuk BAKAN¹, Uğur BAKAN²
}

\begin{abstract}
The change and increasing diversity in communication tools with globalization have ensured the universal presentation of visual elements shaped by local cultural patterns. Today, design products have turned into a strategic tool for many countries in order to reach higher competitive power. As the visual design industry contributes as an important visual communication and marketing tool for different industries within and outside the creative sector, its role in ensuring sustainability becomes even more important. Graphic design is much more effective, direct, and fast than other means of information in order to develop environmental awareness and motivate desired behaviors. The biomimetic graphic is a design process and style that has been spread and passed along throughout today's culture and society via various channels and networks of communication. In today's world, where globalization and associated social and environmental problems are increasing, design education plays an important role in the development of sustainable design products. In design education, the students should be taught the concepts of ecological material selection, environmentally friendly energy use, recycling, reconsideration, and reuse. In this study, the role of biomimicry in visual design education will be examined with sample applications. In addition to new skills and knowledge in design education, sustainability will emerge as an important feature sought in designers soon.
\end{abstract}

Keywords: Biomimicry, visual design, design thinking, sustainable design.

\section{Biomimicry}

Product design is now viewed as a strategic tool for many countries in the early stages of innovation to achieve greater competitiveness. With the eco-design philosophy, the designer is no longer only the person who can develop form, but also the person who must change the production process and behavioral habits in the name of environmental sustainability. At this point, the designer should consider the product's recoverability as well as its aesthetics. To truly determine a product's sustainability or carbon footprint, its entire lifecycle must be tracked. The most important elements for an environmentally friendly design are the selection of a range of materials for printed designs, such as energy, water, paper, inks, solvents, and packaging. Throughout history, designers, engineers, architects, and scientists have turned to nature as a guide in solving many mechanical and structural problems they faced, and have observed the events in detail. The struggle of every

\footnotetext{
${ }^{1}$ Assistant Professor, İzmir Kâtip Çelebi University, Izmir, Turkey. ufuk.bakan@iikc.edu.tr

2 Associate Professor, İzmir Kâtip Çelebi University, Izmir, Turkey. ugur.bakan@ikc.edu.tr
} 
living thing in nature to survive was the inspiration for many people working in various disciplines. Since the early ages of history, many invariant laws have been created by linking phenomena that are similar to natural events as a result of observations and measurements. People's previous experiences in generating ideas are based on raw material, and the components that make up previous experiences are unusually associated and combined when generating creative ideas (Swartz et al., 1998 , p. 8). Thus, it has become possible to transfer the perfect structure of objects in nature and their relations with each other to various fields of science. The relationship of nature with engineering can be decisive in the development of new tools, materials, and mechanical systems, such as being able to fly, swim, jump and run. Researchers studying the lotus plant in rainforests, for example, discovered that despite the moist and muddy environment in which the plant lives, its leaves are spotless and its flowers are very bright. The examinations revealed that the fine hairs on the surface prevent dirt and water from adhering to the surface. The surface properties of the lotus plant have been used in the production of waterproof clothing and dirt-repellent wall paint for the textile and chemical industries, inspiring engineers and designers working in various fields.

Examining nature and living things as reference sources in the search for solutions of different disciplines and using them in the solution of advanced engineering systems forms the field of study of biomimicry. Biomimicry is generally defined as "nature-inspired innovation" or alternatively as "the conscious emulation of life's genius (Benyus, 2002, p. 1). Similar/close concepts such as Biomimicry, Bio-inspired design, and Bionics are used to define biomimicry in the literature (Vincent, 2009). The biomimicry approach, thought to be inspired by nature in response to designers' growing environmental sensitivity, offers numerous opportunities for design education. It is obvious that design, designers, and thus design education can play a significant role in ensuring sustainable futures, especially in today's world where globalization and its associated social and environmental problems are on the rise. The widespread and practical application of biomimicry as a design method remains however largely elusive. It is known that the term biomimicry first appeared in the scientific literature in 1962, and grew in usage particularly amongst material scientists in the 1980s (Aziz \& Sherif, 2015, p. 708).

Academic studies are carried out at three levels based on the basic determinant characteristics of biomimicry organisms. In first-level studies, the structure of biomimicry's natural form is tried to be determined (Benyus, 2002). For example, the African Stenocara insect, which attracts researchers' attention, has a design that helps it survive and find sufficient water resources, although it lives in a dry area that hardly receives any rain most of the year. The complex structure of the insect's shell helps it store the essential nutrients and water and moisture needed to survive in such a climate. Second-level studies investigate biological processes and how they can be imitated in design and engineering (Hayesa et al., 2020). In order to make the aircraft lighter and more efficient with the developments in material technologies, solutions are still sought in nature. There are numerous examples in nature of how to make their aerodynamic structures better to reduce carbon emissions. To make their designs more efficient, 
aeronautical engineers tried to make flight control surfaces more efficient by examining the wing structures of eagles, which are one of the most predatory birds on the earth and can climb and glide to high altitudes in the air. In the final researches, system-level studies focusing on principles, models, and strategies adopted within ecosystems are carried out (Benyus, 2011).

The philosophy of biomimicry is based on the idea that many of the problems that humanity has difficulty in finding solutions to have already been solved in nature (Lurie-Luke, 2014, p. 1502). As a result of the evolution process of the world, many regenerative models of living things have emerged and these existing models have provided resources for many fields (Baumeister et al., 2014). For example, the flying machine, one of Leonardo da Vinci's most famous inventions during the Renaissance, was developed based on the movements of birds and bats (Taylor, 2009). Many animals have shell-like structures of limbs such as horns and hooves that protect their bodies from external threats. These features help the creature survive and hide. In building design, architects such as engineers used Biomimicry in their architectural projects by examining the nature-inspired problems they encountered as a series of values transformations. For example, Mazzoleni explored ways to use animal skins in the construction of performing buildings.

\section{Application of Biomimicry in Graphic Design}

Since the existence of people, they have tried to create aesthetic and functional objects by using the objects around them. Creativity generally takes place as a result of combining elements that do not have a strong bond between them. At first, the concept of creativity, which expressed only a phenomenon related to painting, sculpture, and architectural fine arts, today covers a wide range of design products such as graphics, industry, and photography in science and technique. Creativity definitions can be grouped into three categories as focusing; on the creative product, on the individual characteristics of a creative person who is able to produce new ideas or products, and on the creative process (Runco, 2004, p. 672). Although creativity is seen as one of the general skills found in every person, various research results reveal that creativity aspects of individuals who can think critically and are open to innovations are stronger. Children's anxiety about connecting the perceived forms with the concept or object they want to animate is seen as the beginning of creativity. Therefore, parents and educators should understand the importance of creative activities, attach importance to creative activities and encourage the creativity of students by including creative activities in the classroom (Fox \& Schirrmacher, 2015).

In general, the biggest criticism related to the education system is that the education and training applied are far from critical, problem-solving, and creative thinking. In design education, students read visual elements from a critical perspective and transform them into the design with their cultural codes. In order for a design to be transformed into an effective and aesthetic communication form, it must use the design elements within the framework of the generally accepted 
criteria determined by the design principles. The designer should determine the appropriate method and create the fiction in order for the image to convey the desired message. Starting with the first grade of education, educational processes are a complex structure composed of a school, curriculum, time, method, and teacher, in which perception and interest develop. Many elements in this new environment and system have an impact on students' thinking skills. The educational system's objectives of knowledge, comprehension, application, analysis, synthesis, and evaluation include an increasing intellectual activity from the bottom to the top. It is frequently stated that students must manage their thinking process efficiently to learn the course contents effectively at the teaching levels; otherwise, they will attempt to memorize a large amount of information (Paul \& Elder, 2014, p. 7). In today's design education, it is rarely practiced that students learn by solving problems "with a design team. Design students mostly work individually on their projects that do not help that building teamwork or communication skills between the disciplines (Soibelman et al., 2003).

Basic art education aims to develop students' creative power, observation skills, and ability to express their feelings through art in addition to focusing on the fundamental principles and concepts of art. With this understanding, the Bauhaus School, founded in 1919 by Walter Gropius in Weimar, Germany, began the first systematic design education. The Bauhaus School, which was founded to foster free and experimental studies in art, design, and architecture, attempted to integrate industry, art, and craft in a modernist manner (Frayling, 2007). The Bauhaus Art Movement's influence can still be observed today in the construction of policies or educational reforms aimed at achieving industrialization breakthroughs and the integration of art. Using as much material as possible in art, design, and technology-based courses, as well as supplementing the course with visual elements, improves students' creativity. Since the extension of human imagination is limited to what can be experienced around, when it comes to design material or mechanism, human always draws inspiration from the nature. People's prior experiences are used as raw material for idea generation, and the components of those experiences become unusually related and combined in the process of generating creative ideas (Swartz et al., 1998). Examining the structure of objects in nature and allowing students to apply their perceptions to their designs is a method that has been used in design education for many years. Design elements and principles that form the basis of my visual art education; In addition to all fields of art, it is widely used in architecture, interior architecture, fashion, textile, industrial design, and graphic design education (O'Connor, 2013).

One of the pioneering applications used for the development of creativity and sustainability in design is realized through biomimicry. Biomimicry in design is a fairly ancient approach used to simulate complex forms in nature by analyzing their structure in another product. Today, those working in creative fields, especially architects and engineers, are inspired by nature in order to achieve the optimum level in their designs. The idea of imitating forms or functions existing in nature and using them in creative industries dates back as far as human history. The first examples of this source of inspiration are easily observable designs such as the 
climate or the physiological structure of various living species. In this sense, a chart illustrating the steps to be taken as required to comprehend the structure, distinguishing characteristics, and functions of organisms in nature and to facilitate the transfer of this information on how to solve the problems encountered. Carl Hastrich, an industrial designer, proposed the biomimicry design spiral in 2005 to develop innovative and sustainable design solutions regarding this situation. The design spiral which was developed by Carl Hastrich for the Biomimicry Institute, categorizes the design process as follows: definition, transformation, discovery, analogy, and evaluation (Hastrich, 2006). The first stage of the design spiral implies the initial process of defining problems encountered and determining what needs to be addressed. In addition, the stage in which the expectations you want to be realized in the design are put forward in the first stage constitutes the primary step of this process. The stage of transformation is where these expectations are transformed into biological terms. The discovery phase, on the other hand, is the stage at which nature's strategies for functioning under your expectations are revealed. The analogy stage is where the natural model is applied to the design concept. In other words, it is the stage in which natural selection in nature is imitated or adapted. Sharks, for example, have been observed to move very quickly in the seas despite their muscle density and body weight. It has been concluded that it is possible thanks to the small plaques in the skin which reduce the friction factor. Plaques similar to sharkskin have now been applied to swimmers' swimwear, allowing them to move faster in the pool. The evaluation phase is the time to evaluate your design based on your design brief and Life Principles, and then to decide how you want to use it in your next lap.

In order for a design to function as in the ecological order, it is necessary to model its role in this system very well. A four-stage process is followed to benefit from biomimicry in design education. In the first stage, the student needs to collect data by examining possible natural forms that can be associated with his/her design. In the second stage, which is called the incubation period, the individual carries out single-color draft studies based on the data. Thirdly, in the enlightenment phase, thoughts and ideas that are regarded as irrelevant come together and are filtered. This process is the stage in which the exact lines between the design and the source form are determined and the coloring stage is performed. In the final stage "verification", the design is terminated by placing small corrections and, if necessary, writing (Gabora, 2002). An example of this process in the field of graphic design is given below (Figure 1). Biomimicry examples used in graphic design are as follows: 


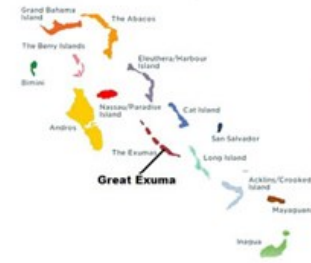

(a)

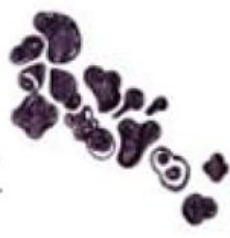

(b)

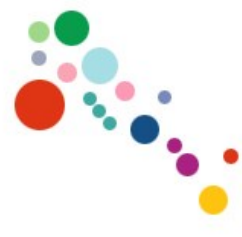

(c)

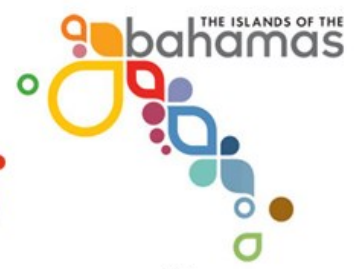

(d)

Fig. 1. Islands of the Bahamas logo created by Duffy \& Partners (Macnab, 2012, p. 120)

Duffy \& Partners of Minneapolis designed a new identity for the Bahamas Ministry of Tourism as part of the country's new tourism promotion strategy. The goal of this identity is to highlight the elements that set it apart from the competitors and grant it a privilege, as well as to offer an original idea and solution. The Bahamas sought a new, more modern approach to appeal to a large number of entrepreneurs in the tropical island tourism market, while also reflecting the island's tourism market, with a market economy largely based on tourism and international financial services. At this point, the solution has been found in using a biomimicry method and taking advantage of the 700 islands forming the structure of the country.

\section{Conclusion}

With the realization of ecological destruction that started with the industrial revolution in the second half of the 20th century, human beings have become more at peace with nature in product development processes. Nature is utilized in the development of products for various sectors, in solving the encountered problems, and also in developing different design solutions in sectors where competition is intense. This approach provides an innovative perspective in the development process of a product and helps to solve the functional problems of the product. In order to adapt these new concepts and approaches in design to both businesses and society as a whole, the curriculum will also show radical changes in the coming years (Guellerin, 2010, p. 9). In our developing society, individuals with creative thoughts need to be raised and these individuals need to be revealed. Children, whose creative abilities are supported from the pre-school period, will grow up to be more successful, productive, and efficient by reflecting these characteristics in all areas of their lives in adulthood.

\section{References}

Aziz, M. S., \& El sherif, A. Y. (2015). Biomimicry as an approach for bio-inspired structure with the aid of computation. Alexandria Engineering Journal, 55(1), 707-714. http://doi.org/10.1016/j.aej.2015.10.015

Baumeister, D. (2014). Biomimicry resource handbook: a seed bank of best practices. CreateSpace

Benyus, J. M. (2002). Biomimicry: innovation inspired by nature. Harper Perennial. 
Fox, J. E., \& Schirrmacher, R. (2015). Art \& creative development for young children. Cengage Learning.

Fox, J. E., \& Schirrmacher, R. (2015). Art \& creative development for young children. Cengage Learning.

Frayling, C. (2007). The New Bauhaus: An art education for the 21st century. Art Libraries Journal, 32(1), 31-37. http://doi.org/10.1017/S0307472200014838

Gabora, L. (2002). Cognitive mechanisms underlying the creative process. In Proceedings of the 4th conference on Creativity \& cognition. 126-133. http://doi.org/10.1145/581710.581730

Guellerin, C. (2010). Design Education: The New Deal, Vitamins for Design. Disegno Industriale, 42-43, 20-31 https://www.diid.it/archivio/42-43.pdf

Hastrich, C. (2006). The Biomimicry Spiral. Biomimicry Newsletter, 4(1), 5-6. https://biomimicry.typepad.com/newsletter/files/biomimicry newsletter v4.1.pd $\underline{\mathrm{f}}$

Hayes, S., Desha, C., \& Baumeister, D. (2020). Learning from nature - Biomimicry innovation to support infrastructure sustainability and resilience. Technological Forecasting and Social Change, 161, 120287. http://doi.org/10.1016/j.techfore.2020.120287

Lurie-Luke, E. (2014). Product and technology innovation: What can biomimicry inspire? Biotechnology Advances, 32(8), 1494-1505. http://doi.org/10.1016/j.biotechadv.2014.10.002

Macnab, M. (2012). Design by nature: Using universal forms and principles in design. New Riders.

O'Connor, Z. (2013). Colour, contrast and gestalt theories of perception: The impact in contemporary visual communications design. Color Research \& Application, 40(1), 8592. http://doi.org/10.1002/col.2185

Paul, R., \& Elder, L. (2014). Critical thinking: Tools for taking charge of your professional and personal life. Pearson Education.

Runco, M. A. (2004). Creativity. Annual Review of Psychology, 55(1), 657-687. http://doi.org/10.1146/annurev.psych.55.090902.141502

Soibelman, L., O’Brien, W., \& Evlin, G. (2003). Collaborative design processes: A class on concurrent collaboration in multidisciplinary design. Journal of Construction Education, $8(2), 78-93$.

http://www.ascjournal.ascweb.org/journal/2003/no2/Summer\%202003,\%20Vol. \%208,\%20No.\%202,\%20pp.\%2077-93.pdf

Swartz, R. J., Fischer, S. D., \& Parks, S. (1998). Infusing the Teaching of Critical and Creative Thinking into Secondary Science: A Lesson Design Handbook. Critical Thinking Books and Software.

Taylor, R. (2009). Reflecting the impossible. Nature, 460(7254), 462-462. http://doi.org/10.1038/460462a

Vincent, J. F. V. (2009). Biomimetics - a review. Proceedings of the Institution of Mechanical Engineers, Part H: Journal of Engineering in Medicine, 223(8), 919-939. http://doi.org/10.1243/09544119jeim561 